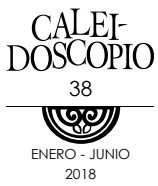

\title{
Camacho (2016) La luz y el caracol. Estudio, lucha y placer en la universidad
}

\author{
Review of Camacho (2016) La luz y el caracol. \\ Estudio, lucha y placer en la universidad
}

SANDRA REYES CARRILLO'

Camacho Sandoval, Salvador. (2016).

La luz y el caracol. Estudio, lucha y placer en la universidad. Aguascalientes: Universidad Autónoma de Aguascalientes.

\section{LA LUZ}

La Universidad Autónoma de Aguascalientes, en su XIX edición de la feria del libro, puso al alcance de la comunidad universitaria y del público en general una colección de nueve libros intitulada "Una introducción para zombis", todos escritos bajo la indicación de hacer accesible el conocimiento a todos aquellos interesados en "el complejo horizonte teórico que, de manera peculiar, genera nuestra contemporaneidad". La luz y el caracol. Estudio, lucha y placer en la universidad forma parte de esta colección.

$\overline{1 \quad \text { sareca@hotmail.com }}$
La luz y el caracol es un libro que no sólo cumple con hacer accesible el conocimiento, pues tiene un lenguaje sencillo y una escritura amena, lúcida y provocativa, sino que además incita a la lectura sin pausa, pero sobre todo, a la reflexión en torno a su objeto de estudio: la universidad, su origen y sus objetivos.

Esta obra, repositorio de una historia enriquecida por la experiencia, ha sido escrita, en palabras del autor, desde la subjetividad; es decir, sus 222 páginas, distribuidas en cuatro capítulos, son producto de una narración personal, lo que cumple a cabalidad con el objetivo del autor: ofrecer un acercamiento cordial y 
amigable sobre el tema, aunque hay que mencionar que sin dejar de ser crítico y reflexivo.

Algunas de las preguntas que hace y se hace el autor son: ¿Por qué la educación?; ¿qué lugar ocupa la universidad en la sociedad contemporánea?; ¿por qué es necesario recuperar el humanismo de la universidad?; ¿por qué la lucha a favor del autogobierno en la universidad?; ¿por qué debemos aspirar a un futuro ideal para las universidades públicas y autónomas?

Para dar respuesta a las preguntas anteriores, para dar luz, el autor parte de la siguiente premisa:

la educación no es la varita mágica con la cual se puedan hacer todos los cambios deseables y necesarios, pero $[\ldots]$ sin ella no se pueden lograr dichos cambios [...]. La educación nos ayuda a construir por nosotros mismos los instrumentos que nos transforman desde adentro, en profundidad; incluso, puede ser un medio clave para liberar a las personas y a los pueblos de toda servidumbre (pp. 18 y 19).

En esta liberación de la que habla Salvador Camacho, la educación superior ocupa un papel protagónico, toda vez que las instituciones de educación superior, según sus palabras, son institu- ciones que generan y transmiten conocimiento especializado, y muchas veces participan en el análisis, la polémica y la definición de rumbos en la vida de los pueblos. La afirmación anterior otorga el paso a la siguiente pregunta: ¿cuál es el deber de las instituciones de educación superior? Salvador Camacho, sin dejar de ser amigable, en el capítulo IV ensaya una respuesta, y su pluma se vuelve exquisitamente crítica: hay que recuperar el humanismo, pues ante la creciente complejidad de la vida de las universidades, que a su vez ha permitido la diversificación de sus funciones, se han implementado acciones que se confunden entre complementarias y fundamentales, como son la comercialización de los servicios, las nuevas estructuras de gestión, la participación del sector privado, los apoyos internacionales a programas específicos, las nuevas relaciones con el gobierno, la flexibilización de la legislación universitaria, entre otras.

Como consecuencia al planteamiento anterior, el autor se pregunta

si todo esto es para que las universidades cumplan con lo que la sociedad espera de ellas, sobre todo los grupos sociales con bajos niveles de vida, o para que estas instituciones respondan 
a los intereses, necesidades y planes de un grupo reducido de personas, gobiernos y organismos internacionales, los cuales mantienen como prioridad la permanencia en el poder, la rentabilidad y el lucro (p. 182).

Las universidades, dice Camacho, han entrado en una dinámica con rasgos perversos y absurdos que subordinan las tareas fundamentales de la universidad a funciones administradoras. No hay que dejar de resaltar que lo dice un investigador que escribe desde una institución de educación superior, cuya publicación está contribuyendo a que la universidad cumpla una de sus funciones sustantivas: la difusión. Él, por su parte, cumple con dar luz, con generar conocimiento, con dar respuesta a estas preguntas o, donde no la hay, buscarla, provocarla.

\section{EL CARACOL}

"Mi padre nació en un rancho de bello nombre: Puerta de Luna, cerca de Teocaltiche, Jalisco" (p. 27). Con estas palabras inicia el capítulo I de La luz y el caracol. Creo que no es coincidencia que el autor comience por mencionar un lugar, pues los lugares, puntos de partida en ocasiones pero des- tinos finales muchas otras, serán significativos en la historia de vida del autor y, por lo tanto, en su libro.

Según una de las definiciones de esta palabra, un caracol es cada una de las vueltas que hace un camino. Éste es, entonces, el modo en que Salvador Camacho ha decidido contar la historia de la universidad: partiendo de lo que conoce, de las vueltas que ha hecho y de los lugares de donde ha partido. Este estilo se mantiene hasta el final, lo que resulta acertado, pues la lectura se vuelve accesible, placentera. Y así, Aguascalientes, la Ciudad de México, Guanajuato, Chicago, Río de Janeiro, Bogotá, Cuba, Argentina y Nicaragua, descubrimos, tienen algo en común: instituciones de educación superior que guardan, si no una estrecha relación con el autor, sí un vínculo cobijado por una historia.

Este último elemento, la historia, está presente también en cada capítulo del libro. Así, sobre el origen de la universidad, llegamos a conocer que la primera universidad se creó en Bolonia hace casi mil años; la segunda en Palermo y la tercera en París (p. 76); y que en América Latina la primera universidad no sería creada sino hasta el siglo XVI. De la mano de esta historia, encontramos en la lectura pasajes 
de historia personal: "En 1982, Yolanda y yo, junto con un pequeño grupo de amigos, nos sentamos en el pasto recién cortado del jardín de lo que antes fuera la casa de la esposa del dictador Anastasio Somoza y ahora una Casa de Cultura en Managua, Nicaragua, para escuchar a tres grandes literatos, dos de ellos importantes en la literatura universal: Gabriel García Márquez y Julio Cortázar" (p. 117). Estos intersticios personales hacen de la lectura, por momentos, una novela de aventuras. Así, en La luz y el caracol, el lector puede encontrar no sólo historia, investigación, rigurosidad, reflexión; también, y en múltiples páginas, puede encontrar poesía.

\section{ESTUDIO, LUCHA Y PLACER}

Salvador Camacho realizó sus estudios de maestría en el Centro de Investigación y Estudios Avanzados (CINVESTAV) del Instituto Politécnico Nacional (IPN), donde aprendió, de Olac Fuentes Molinar, sobre las universidades. Éste es uno de los nombres clave que figuran en el libro, pues ayudan a entender tanto la formación del autor como el objeto de estudio de la obra. Entre otros nombres clave se encuentran el de Susana Quintanilla, maes- tra de posgrado del autor, y el de Mary Kay Vaughan, cuyo nombre se lee desde la dedicatoria ("Para Mary Kay Vaughan, con cariño y gratitud") y a quien el autor describirá con admiración como una estadounidense brillante y sensible. Fue Mary Kay, además, quien brindó una oportunidad al autor: la posibilidad de estudiar el doctorado en Chicago. Para Camacho, estudiar fuera de la ciudad de origen, sobre todo cuando ésta se encuentra en provincia, es indispensable.

Así, para el autor, estudiar en la Ciudad de México implica aprovechar lo que en "provincia" no se tiene: un ambiente cultural y académico de relevancia y un lugar donde se vive y aprecia el pulso de la política del país (p. 35). Ahora bien, estudiar fuera del país, en una ciudad como Chicago, en una universidad que cuenta con un gran número de premios Nobel, multiplica cualquier horizonte y oportunidad de aprendizaje. La luz y el caracol, por lo tanto, es también una invitación a trascender fronteras, a realizar estudios fuera de la ciudad de origen para poder realizar un intercambio cultural, para renovar la visión que como estudiantes hemos formado de las cosas y situaciones, para conocer nuevas personas y aprender otros idiomas.

Para Salvador Camacho escribir es, intuyo, marchar para pro- 
testar, tomar la universidad, alzar la voz, luchar. Aunque es cierto también que el autor ha salido por las calles a marchar:

Estudiando el proyecto educativo, la reforma agraria y otras medidas que impulsó [...] Lázaro Cárdenas del Río, estuve atento al nuevo movimiento cardenista, incluso marché al lado de viejos campesinos con overol y sombrero de ala ancha que recordaban al 'Tata Cárdenas' y al lado de los jóvenes punketos de los barrios marginados de la ciudad que también veían en el nuevo cardenismo una alternativa política de cambio y mejora social (p. 36).

En La luz y el caracol, Salvador cambia la marcha por la pluma, con la cual escribe democracia. Guarda la fe del rebelde que sale a protestar. ¿Fe en qué? En recuperar el humanismo de la universidad, en la autonomía, en la educación como instrumento transformador. Algunos autores creen que sólo la crítica es posible; otros tienen la esperanza de que el cambio es posible. Salvador es de los segundos: "escribí un ensayo $[\ldots]$ Allí procuré $[\ldots]$ desmitificar el discurso de la institución con sus presuntos logros dignos de imitación. De cerca, como maestro, veía muchos problemas y me disgustaba el autoelogio parro- quial; pero al mismo tiempo, reconocía una vía diferente de hacer universidad, considerando nuevas formas de organización y planeación" (pp. 33 y 34).

Salvador critica las nuevas características de la universidad desde la propia universidad y, más aún, ensayando sus ideas en una publicación de una editorial universitaria. No existen filtros en su escritura; al contrario, se lee tenacidad y las palabras de un autor apasionado por su lugar de trabajo. Y es que la universidad es, según él mismo narra, su segunda casa; para Camacho es un verdadero placer trabajar en la soledad de su cubículo, hacer investigación, interactuar con sus colegas y enseñar a sus alumnos (p. 40).

Estudio, lucha y placer conforman la tríada presente en cualquier institución de educación superior con historia, de cualquier institución de calidad. Y digo "de calidad" no sin detenerme a reflexionar. En el capítulo IV, el autor menciona que "Ni la SEP, ni la ANUIES ni el CONACyT están trabajando para hacer de la educación superior una educación de calidad que responda a los retos que enfrenta el país" (p. 170); no obstante, el autor reflexiona también sobre el aumento que ha habido de universidades privadas ante el creciente egreso de estu- 
diantes de bachillerato: "han aparecido universidades privadas que se multiplican sin control. Los requisitos que se solicitan para abrir una universidad y crear carreras fácilmente pueden cubrirse, por lo cual la oferta educativa de algunas universidades nuevas es muy mala" (p. 171). El reto, por lo tanto, es grande: incrementar la calidad de la educación superior en México, que va de la mano de controlar el aumento de las universidades privadas.

La luz y el caracol es un libro para ser leído de principio a fin. Por su tamaño, puede ser leído fácilmente en el metro, en el ban- $\mathrm{co}$, en la universidad; mientras se viaja, mientras se espera. Es un libro diseñado para jóvenes, pero que puede ser leído por cualquiera que esté interesado en conocer el origen de la universidad y en reflexionar acerca del estado actual de la educación superior. Su lectura, indiscutiblemente, brindará conocimiento y cederá el paso a la reflexión.

La edición no venal de este libro se encuentra en formato electrónico en la página http:// www.uaa.mx/direcciones/dgdv/ editorial/, y su edición en papel se halla a la venta en la librería universitaria. 